\title{
The effect of dexamethasone on mucosal immunity of uterine tissue during
} pregnancy in rat

\author{
Faheim El Bahay Wehaish, Youssef Elseady and Nada Mohamed Ali Hashem \\ Department of physiology, Faculty of Veterinary Medicine, Mansoura University, Mansoura, Egypt.
}

\section{ABSTRACT}

\begin{abstract}
Disturbances in early pregnancy immunity affect embryo development, endometrial receptivity, placental development, fetal growth and lead to subfertility, dexamethasone is a synthetic glucocorticoid used for treatment of various complications. Immune cells and cytokines were examined during the early pregnancy in twenty-four female rats and six male rats for mating. Rats were grouped into two group control and dexamethasone treated by a dose of $50 \mu \mathrm{gm} / \mathrm{kgm}$ body weight daily starting from one week before mating and persisted for one week after pregnancy. Blood samples were collected from each rat at $5 \mathrm{hrs}$ and at $1,3,7$ day of pregnancy. Extracted RNA was subjected to real time PCR to determine mRNA levels for immune related genes interleukin1a(IL1A) and interleukin 10(IL10). Histopathological examination was done to uterus in order to detect leukocyte infiltration in uterine tissue. Results showed that significant increase in white blood cell count mainly eosinophil at $5 \mathrm{hrs}$ and lymphocyte at three and seven day of pregnancy of dexamethasone treated group. Moreover, TNF, C-reactive protein and progesterone were increased mainly at seven day of pregnancy of dexamethasone treated group. Similarly, interleukin 1alpha and interleukin 10 significantly increased at $5 \mathrm{hrs}$ and one day of pregnancy of dexamethasone treated group. In contrast, serum levels of total antioxidant capacity and estrogen were decreased significantly at $5 \mathrm{hrs}$ and seven day in dexamethasone treated group. Histopathological examination of uterus revealed leukocytic infiltration especially neutrophil and few eosinophils at five hours and one day of gestation then eosinophil become absent at 3day and seven day of dexamethasone group. Epithelial height and uterine gland diameter significantly increased at $5 \mathrm{hrs}$, three day and seven days of gestation of dexamethasone treated group. The present investigation demonstrated that using of dexamethasone by dose of $50 \mu \mathrm{gm} / \mathrm{kgm}$ during early pregnancy had a conflicting impact on some immune cytokines and parameters and may reflect a harmful response of immune system toward early period of pregnancy.
\end{abstract}

Keywords: Immunity, Gestation, Cytokines, Immune cells, Dexamethasone.

\section{INTRODUCTION}

Maternal stress is one of most important reasons for unsuccessful pregnancy (Gyorffy et al., 2005). Key regulators of the conception and implantation events are maternal tract cytokines and immune cells within the female reproductive tract, while the receptivity of the endometrium is dependent on immune cells present at implantation site (Thompson et al., 2005). In mice and rats, implantation occurs between days 4 and 5 of pregnancy, considering the first day of pregnancy as the day on which a vaginal plug or spermatozoa are present in the vagina (Parr et al., 1986).

One of glucocorticoid is dexamethasone, commonly administered to pregnant women at risk of premature delivery for stimulating lung maturation (Mesquita et al., 2009). In fact, prematurely neonates treated with dexamethasone have at school age low plasma dexamethasone levels during and after exposure to a psychosocial stress test when compared to prematurely born non-treated children (Karemaker et al., 2008).
Cortisol is commonly used as a stress marker because its production by the adrenal cortex tends to increase as a result of energetic, immunological, and psychological challenges. Treatment with dexamethasone in animal models consistently suggests a long-term impact on the immune function as affecting structure of the thymus (Dietert et al., 2003), T cell proliferation (Coe and Lubach, 2000), cytokine production (Dietert et al., 2003) and in the predisposition to autoimmune disorders (Bakker et al., 2000).

Glucocorticoids are well recognized anti-inflammatory and immunomodulatory agents Rasmussen et al., (1998). However, administration of a unique dose of dexamethasone 10-20 mg used after insemination did not improve pregnancy rates (Vandaele et al.,2010).

Additionally, (Zone et al., 1995) reported that oral administration of dexamethasone appeared to be a potentially useful pharmacologic treatment for the termination of unwanted pregnancy in female dogs. Furthermore, (Gur et 
al.,2004) showed that administration of glucocorticoids to women in the first trimester significantly increased the incidence of miscarriages compared to the rate observed in control patients.

It has been well established that glucocorticoids have inhibitory effects on a broad range of specific immune responses mediated by T and B cells (Fahey et al., 2006).

Similarly, (Sugimoto et al., 2003) found that the antiinflammatory effects of glucocorticoids mediated by the inhibition of leukocyte migration. In contrast, (Deloia et al., 2002) demonstrated that the frequency of uterine macrophages and UNK cells had a direct relationship with serum estrogen levels. Warning et al., (2011) suggested that the administration of high dose of dexamethasone to pregnant mice during early pregnancy can directly or indirectly alter the frequency of uterine macrophages and uNK cells.

During pregnancy, the peripheral specific immune response is shifted away from a type 1 cellular immune response towards a type 2 humoral immune response (Veenstra van Nieuwenhoven et al., 2002). During rat pregnancy both monocyte and granulocytes increased in number in the circulation especially monocytes during pregnancy, especially in the first trimester but decreases as gestation advances. (Faas et al., 2000).

Sallinen et al., (2000) showed that utero placental tissue produces an array of anti-inflammatory cytokines as interleukin 10 that expressed in the uterus, oviducts and ovaries of cycling mice and during pregnancy in the myometrium and cervix. Thus, the balance between proinflammatory cytokines as tumor necrosis factor (TNF) and interleukin 1a and anti-inflammatory cytokines is essential to a successful pregnancy (Hanna et al., 2000). IL1A is one of the main cytokines that participates in the local regulation of many reproductive events. IL1A has a role in regulating ovulation (Rae et al., 2004). Haider and Knofler, (2009) showed that TNF- $\alpha$ influence hormone synthesis, placental architecture, embryonic and follicle development, steroidogenesis, uterine cyclicity, placental differentiation and parturition. TNF- $\alpha$ in low level is essential for early events in pregnancy such as implantation, but high levels of TNF- $\alpha$ may be deleterious to pregnancy later during gestation (Haider and Knofler, 2009).

Uchenna and Fidelis (2005) hypothesized that Pregnancy is a stressful condition as lead to increased levels of oxidants and therefore reduce total antioxidant capacity (TAC).

C-reactive protein (CRP) is a sensitive marker of systemic inflammation and is primarily synthesized in hepatocytes in response to infection and tissue injury. Production of CRP is stimulated by the release of proinflammatory cytokines including interleukin-1, interleukin-6, and tumor necrosis factor-alpha. (Dealtry et al., 2000).

Hunt and Miller (1998) showed that progesterone reduced macrophage migration into the murine uterus, while (Kitzmiller and Rocklin, 1980) showed that estrogen, progesterone and human chronic gonadotrophin not affect migration of macrophage cells in guinea pigs.

(Goldman and Shalev, 2007) showed that progesterone affect immunity mainly at pregnancy concentrations. These effects are primarily mediated via the intracellular progesterone receptors (PR), PR-A and PR-B, which act as transcription factors (Kowalik et al., 2013).

Upon pregnancy, estrogen is shown to promote uterine blood flow, myometrial growth, stimulate breast growth and at term, promote cervical softening and expression of myometrial receptors. In addition to, estrogen was suggested to affect different immune cell populations in their number and function and there by contributes to fetal tolerance (Levin and Pietras,2008).

Leukocytic infiltration during early pregnancy indicated that decidual natural killer cells make up around $30 \%$ of the uterine stromal compartment mainly at the implantation site where they are found scattered throughout the stroma and thickly clustered around glands and spiral arteries in the uterus. (Cooper et al.,2001). So, the aim of the present study was to evaluate the immunological effect of dexamethasone on some cytokines, immune cells and mucosal immunity of uterine tissue in rat during pregnancy.

\section{MATERIALS AND METHODS}

\section{Experimental animals}

The study was conducted on twenty four mature female Sprague Dawely rats and four mature male rats weighting 200250 g. B.wt, divided into two groups, twelve in each group. All animals purchased from laboratory animal house, Helwan Egypt. They were housed in separate cages in physiology department, Faculty of veterinary medicine, Mansoura University. Rats were kept in a controlled environment for two weeks before the experiment for accommodation; maintained under normal condition and were fed a basal control diet. Water and diet were given ad-libitum throughout the experimental period that extended for one month. All females were examined for detection of stage of estrus cycle by taking vaginal smear and examine it under microscope to determine which female in estrous phase to determine best time of insemination according to the methods of (Felicio et al.,1984).

\section{Diet and additives}

The basal diet was prepared by Faculty of Agriculture, Mansoura University according to standard level of NRC. The 
diet produced in the form of pellet and is admitted to all groups of the study.

\section{Dexamethasone}

Dexamethasone is immunosuppressive substance that was purchased in the form of drug from (AMRIYA) pharmaceutical company, the commercial name is Dexamethasone Sodium phosphate. The dose is 50 microgram $/ \mathrm{kg} \mathrm{I} / \mathrm{M}$ injection daily starting by one week before mating and persisted for one week after mating.

\section{Material used for real time PCR}

- RNeasy Mini Kit Catalogue no.74104: RNeasy Mini Kit (for purification of total RNA from animal cells, animal tissues, and yeast, and for cleanup of RNA from crude RNA preps and enzymatic reactions (e.g., DNase digestion, proteinase digestion, RNA ligation, and labeling reaction)

- Ethanol 96\% Applichem (It was diluted to 70\% using DW).

- ß-Mercaptoethanol Sigma Aldrich.

\section{Blood and tissue samples}

At different time point ( $5 \mathrm{hrs}, 1$ day, 3 days and 7 days) after mating, blood samples were collected from retro orbital venous plexus and separated into two parts one for hematological assay and other for serum separation that stored frozen until hormonal and biochemical assay. Tissue sample were collected after anesthesia and slaughters from uterus of three rats of two group at each time point and store frozen for PCR assay and other tissue parts stored in $10 \%$ neutral buffer formaldehyde for histopathological examination.

H- PCR

\section{H.1- RNA extraction}

- RNA extraction from tissue samples was applied using QIAamp RNeasy Mini kit (Qiagen, Germany, GmbH) when 30 $\mathrm{mg}$ of the tissue sample was added to $600 \mu \mathrm{l}$ RLT buffer containing $10 \mu \mathrm{l} \quad \beta$-mercaptoethanol per $1 \mathrm{ml}$. For homogenization of samples, tubes were placed into the adaptor sets, which are fixed into the clamps of the Qiagen tissue Lyser. Disruption was performed in 2 minutes highspeed $(30 \mathrm{~Hz})$ shaking step. One volume of $70 \%$ ethanol was added to the cleared lysate, and the steps was completed according to the Purification of Total RNA from Animal Tissues protocol of the QIAamp RNeasy Mini kit (Qiagen, Germany, $\mathrm{GmbH}$ ).

- N.B. On column DNase digestion was done to remove residual DNA.
H.2- Preparation of PCR Master Mix according to Quantitate SYBR:

\section{Oligonucleotide Primers}

Primers used were supplied from Metabion (Germany) and are listed in table (1).

CDNA synthesis

RNA was reversely transcribed into CDNA using Thermo Scientific RevertAid Reverse Transcriptase (Thermo scientific). Where 20- $\mu \mathrm{l}$ reaction containing $4 \mu \mathrm{l}$ of the $5 \mathrm{X}$ Reaction Buffer, $1 \mu \mathrm{l}$ of RevertAid Reverse Transcriptase $(200 \mathrm{U} / \mu \mathrm{L}), 0.5$ $\mu$ of $(20 \mathrm{U})$ Thermo Scientific ${ }^{\mathrm{TM}}$ RiboLock RNase Inhibitor (\#EO0381), $0.5 \mu \mathrm{l}(20 \mathrm{pmol})$ Random hexamer (\#SO142), $2 \mu \mathrm{l}$ of dNTP Mix [10 mM each (\#R0191)] $10 \mu \mathrm{l}$ of water, and $2 \mu \mathrm{l}$ of RNA template. The reaction was performed in an Applied biosystem 2720 thermal cycler. Mixture was incubated for 10 min at $25^{\circ} \mathrm{C}$ followed by $60 \mathrm{~min}$ at $42^{\circ} \mathrm{C}$.

\section{SYBR green $r t-P C R$}

Primers were utilized in a $25-\mu \mathrm{l}$ reaction containing 12.5 $\mu l$ of the 2x QuantiTect SYBR Green PCR Master Mix (Qiagen, Germany, $\mathrm{GmbH}), 0.5 \mu \mathrm{l}$ of each primer of $20 \mathrm{pmol}$ concentration, $10.5 \mu \mathrm{l}$ of water, and $1 \mu \mathrm{l}$ of cDNA template. The reaction was performed in a Stratagene MX3005P real time PCR machine. A primary denaturation step was done at $94^{\circ} \mathrm{C}$ for $15 \mathrm{~min}$, followed by 40 cycles of $94^{\circ} \mathrm{C}$ for $15 \mathrm{sec}$., $60^{\circ} \mathrm{C}$ for $30 \mathrm{sec}$. and $72^{\circ} \mathrm{C}$ for $30 \mathrm{sec}$. A Dissociation curve was performed for one cycle including $94^{\circ} \mathrm{C}$ for $1 \mathrm{~min}$., $60^{\circ} \mathrm{C}$ for 1 min. and $94^{\circ} \mathrm{C}$ for $1 \mathrm{~min}$.

\section{Analysis of the SYBR green rt-PCR results}

Amplification curves and ct values were determined by the Stratagene MX3005P software. To estimate the variation of gene expression on the RNA of the different samples, the CT of each sample was compared with that of the positive control group according to the " $\Delta \Delta \mathrm{Ct}$ " $\left(\Delta \Delta C t=\Delta C t_{\text {reference }}-\Delta C t_{\text {target }}\right)$ method stated by Yuan et al., (2006).

\section{I- Tissue sampling}

Both uterine horns were excised from all pregnant rats and one sample from each horn was taken and fixed immediately in $10 \%$ neutral buffered formalin solution. All specimens were routinely processed in ascending grades of ethyl alcohol $(80 \%, 90 \%, 100 \%)$, cleared in xylene and embedded in paraffin wax to prepare $5 \mu \mathrm{m}$ thick paraffin sections. Sections of $5 \mu \mathrm{m}$ thickness were cut and picked up on uncoated slides, dried, deparaffinized with xylene (3x3minutes) and rehydrated with graded alcohol (5×2minutes), washed and stained with H\&E according to Bancroft and Gamble, (2007). Uterine sections from day 7 of gestation were additionally stained with Masson's trichrome. 
The stained sections were dehydrated in absolute ethyl alcohol, cleared in xylene and mounted with Mount-Quick liquid cover glass medium to the surface of the slides. Histological changes were examined by light microscopy (binocular, Olympus). Histological pictures were picked up using Digital camera (Canon 5 mega pixels, 3.2x optical zoom).

J- Statistical analysis:

The data of histopathological examination of morphometric measurements of epithelial height and diameter of uterine glands were subjected to student $T$ test to differentiate between control and dexamethasone treated group. Data were expressed as means \pm standard errors. Difference between means was considered significant when $(P$ $<0.05)$.

The remaining data obtained for rats of the two experiments were expressed as means SE. Statistical analysis of data was carried out by the computer package program (SPSS,1994) version 16, using the two-way analysis of variance
M-ANOVA between variables at group level and time level followed by Duncans Multiple Range Test (DMRT) for testing the significance differences between variables(M-stat,2009).

Table 1. Oligonucleotide primers and probes used in SYBR Green real time pcr

$\begin{array}{lll}\begin{array}{l}\text { Target } \\ \text { gene }\end{array} & \text { Primers sequences } & \text { Reference } \\ \text { Rat ß-actin } & \text { TCCTCCTGAGCGCAAGTACTCT } & \begin{array}{l}\text { Banni et al., } \\ (2010)\end{array} \\ & \text { GCTCAGTAACAGTCCGCCTAGAA } & \\ \text { IL10 } & \text { GCGGCTGAGGCGCTGTCAT } & \begin{array}{l}\text { Shynlova et al., } \\ \text { CGCCTTOOGTAGACACCTTGGTCTTG }\end{array} \\ \text { IL1 alpha } & \text { GGC TAA GTT TCA ATC AGC CCT TT } & \\ & \text { AGG TGC TGA TCT GGG TTG GAT } & \text { (2014) } \\ \end{array}$

\section{RESULTS}

Table 2. Effect of dexamethasone on (total number of WBCs $\times 103 / \mu 1$, neutrophil $\%$, lymphocyte $\%$, eosinophil\%, basophil $\%$ and monocyte $\%$ at different time of experiment (5hrs, 1day, 3days and 7 days):

\begin{tabular}{|c|c|c|c|c|c|c|c|c|c|c|c|c|}
\hline Group & \multicolumn{2}{|r|}{ Wbcs } & \multicolumn{2}{|c|}{ neutrophil } & \multicolumn{2}{|c|}{ Iymphocyte } & \multicolumn{2}{|c|}{ esinophil } & \multicolumn{2}{|c|}{ basophil } & \multicolumn{2}{|c|}{ monocyle } \\
\hline Time & control & dexamethasone & control & dexamethasone & control & dexamethasone & control & dexame & control & dexamethasone & control & dexam \\
\hline Shrs & $7.00 \pm 1.15 \mathrm{Cd}$ & $8.20 \pm 0.75 \mathrm{BC}$ & $19.00 \pm 5.20 \mathrm{Ac}$ & $15.87 \pm 2.17 \mathrm{Ca}$ & $72.00 \pm 4.93 \mathrm{Cb}$ & 75.00_4.40AC & $2.67 \pm 0.33 \mathrm{Cc}$ & $3.93 \pm 1.17 \mathrm{Ba}$ & $1.33 \pm 0.33 \mathrm{Ab}$ & $1.00 \pm 0.01 \mathrm{Ba}$ & $5.00 \pm 0.58 \mathrm{Aa}$ & 4.20 $1.20 \mathrm{Ba}$ \\
\hline day & $9.23 \pm 0.72 \mathrm{Cc}$ & $10.40 \pm 1.75 \mathrm{Ba}$ & $18.67 \pm 1.33 \mathrm{Ad}$ & $13.60 \pm 1.03 \mathrm{Cc}$ & $75.00 \pm 2.65 \mathrm{Ba}$ & $78.60+2.46 \mathrm{Aa}$ & $3.67 \pm 0.33 \mathrm{BD}$ & $3.17 \pm 1.12 \mathrm{Bb}$ & $1.67 \pm 0.33 \mathrm{Aa}$ & $1.00 \pm 0.01 \mathrm{Ba}$ & $4.33+0.88 \mathrm{Ab}$ & 3.63 $50.33 \mathrm{BD}$ \\
\hline Bday & $10.33 \pm 0.44 \mathrm{Ba}$ & a $8.84+0.34 \mathrm{Cb}$ & $20.00 \pm 1.00 \mathrm{Ab}$ & 15.27+0.41 Ca & $69.67+0.88 \mathrm{CC}$ & $78.60 \pm 1.50 \mathrm{Aa}$ & 4.00 $00.00 \mathrm{Aa}$ & $2.07 \pm 0.52 \mathrm{Cd}$ & $1.00 \pm 0.01 \mathrm{AC}$ & $1.00 \pm 0.01 \mathrm{Aa}$ & $5.00 \pm 0.58 \mathrm{Aa}$ & $3.07 \pm 0.58 \mathrm{BC}$ \\
\hline day & $9.47 \pm 0.26 \mathrm{Ab}$ & $7.00 \pm 0.93 \mathrm{Bd}$ & $21.67 \pm 1.67 \mathrm{Aa}$ & $14.23 \pm 1.29 \mathrm{Cb}$ & $69.33 \pm 1.20 \mathrm{CC}$ & $77.80 \pm 3.51 \mathrm{Ab}$ & $3.33 \pm 0.33 \mathrm{Bb}$ & $3.27 \pm 1.13 B C$ & $1.33+0.33 \mathrm{Ab}$ & $1.00 \pm 0.01 \mathrm{Ba}$ & $4.33+0.33 \mathrm{Ab}$ & $3.70 \pm 1.19 B b$ \\
\hline
\end{tabular}

Table 3. Effect of dexamethasone on progesterone(ng/ml) and estrogen (ng/ml) level among different time (5hrs, 1day, 3days and 7 days) of pregnancy during experiment:

\begin{tabular}{|c|c|c|c|c|}
\hline Group & \multicolumn{2}{|c|}{ Estrogen } & \multicolumn{2}{c|}{ Progesterone } \\
\hline Time & Control & Dexamethasone & Control & Dexamethasone \\
\hline 5hrs & $48.43 \pm 0.86 \mathrm{Aa}$ & $37.13 \pm 5.16 \mathrm{Cb}$ & $39.47 \pm 0.69 \mathrm{Cc}$ & $62.17 \pm 2.48 \mathrm{Bc}$ \\
\hline 1day & $45.83 \pm 2.88 \mathrm{Ab}$ & $32.47 \pm 2.37 \mathrm{Cc}$ & $48.43 \pm 0.67 \mathrm{Cb}$ & $69.93 \pm 2.05 \mathrm{Ab}$ \\
\hline 3day & $41.23 \pm 1.13 \mathrm{Ac}$ & $38.80 \pm 3.69 \mathrm{Ba}$ & $57.83 \pm 0.38 \mathrm{Ca}$ & $73.97 \pm 2.38 \mathrm{Aa}$ \\
\hline 7day & $46.60 \pm 2.31 \mathrm{Cb}$ & $38.40 \pm 3.35 \mathrm{Ba}$ & $58.67 \pm 1.82 \mathrm{Ca}$ & $72.27 \pm 3.36 \mathrm{Aa}$ \\
\hline
\end{tabular}

-Capital litters indicated that means within the same column in the same parameter have different letter are significant at $(\mathrm{P}<0.05)$. -Small litters indicated that means within the same rows on the same parameters carry different letter are significant at $(\mathrm{P}<0.05)$. 
Table 4. Effect of dexamethasone on TAC ( $\mu \mathrm{mol} / \mathrm{g} \mathrm{FW})$, TNF (pg / $\mathrm{ml}$ ) and CRP (mg/L) level among different (5hrs,1day, 3days and 7 days) of pregnancy of experiment.

\begin{tabular}{|c|c|l|l|l|l|l|}
\hline Group & \multicolumn{2}{|c|}{ CRP } & \multicolumn{2}{c|}{ TNF } & \multicolumn{2}{c|}{ TAC } \\
\hline Time & Control & Dexamethasone & Control & Dexamethasone & \multicolumn{1}{c|}{ Control } & Dexamethasone \\
\hline 5hrs & $6.50 \pm 0.55 \mathrm{Cb}$ & $12.33 \pm 1.10 \mathrm{Ab}$ & $50.90 \pm 0.80 \mathrm{~B}$ & $60.20 \pm 1.54 \mathrm{~A}$ & $0.58 \pm 0.01 \mathrm{Aa}$ & $0.25 \pm 0.03 \mathrm{Cb}$ \\
\hline 1day & $6.03 \pm 0.15 \mathrm{Cc}$ & $12.57 \pm 1.41 \mathrm{Ab}$ & $50.37 \pm 0.99 \mathrm{C}$ & $69.67 \pm 1.42 \mathrm{~A}$ & $0.51 \pm 0.02 \mathrm{Ab}$ & $0.33 \pm 0.04 \mathrm{Ba}$ \\
\hline 3day & $6.27 \pm 0.22 \mathrm{Cb}$ & $12.53 \pm 1.53 \mathrm{Ab}$ & $48.77 \pm 3.13 \mathrm{~B}$ & $69.27 \pm 5.66 \mathrm{~A}$ & $0.49 \pm 0.01 \mathrm{Ac}$ & $0.23 \pm 0.02 \mathrm{Cb}$ \\
\hline 7day & $6.70 \pm 0.46 \mathrm{Ca}$ & $13.20 \pm 1.23 \mathrm{Aa}$ & $40.03 \pm 0.75 \mathrm{C}$ & $73.20 \pm 2.89 \mathrm{~A}$ & $0.49 \pm 0.02 \mathrm{Ac}$ & $0.31 \pm 0.07 \mathrm{Ca}$ \\
\hline
\end{tabular}

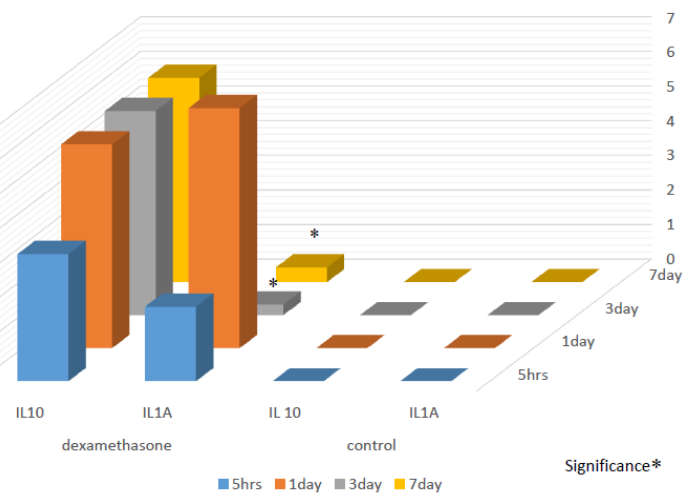

Figure 1. Effect of dexamethasone on IL 1a and IL 10gene concentration at different time of experiment
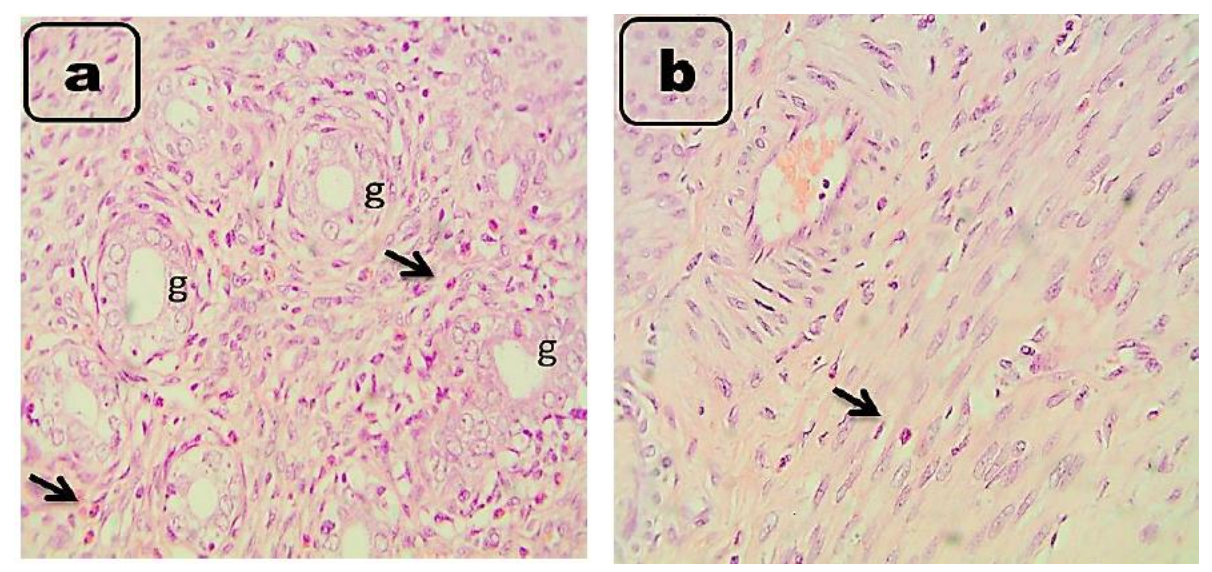

Figure 2. Microscopic picture shows rat uterus after 5 hours of gestation shows heavy eosinophils infiltration in superficial endometrium (arrows) (a) and in between the uterine glands (g) (arrows) (a) in control rats. Few stromal cells density and very few eosinophils infiltrations are seen in superficial endometrium (arrows).Very few eosinophils infiltration is seen in myometrium (arrow) (b) with congested blood vessels in perimetrium (arrows) in dexamethasone treated rats. 

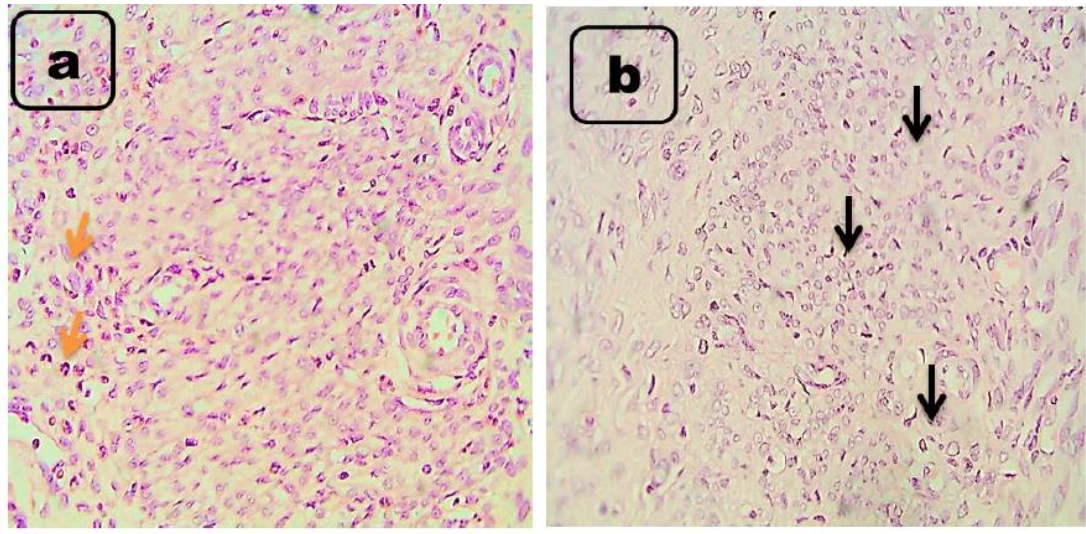

Figure 3. Microscopic picture shows rat uterus at 1 day of gestation shows eosinophils infiltration in myometrium (orange arrows) (a) in control rats. Few PMNs infiltrations are seen in myometrium (black arrows) (b) in dexamethasone treated rats (b).

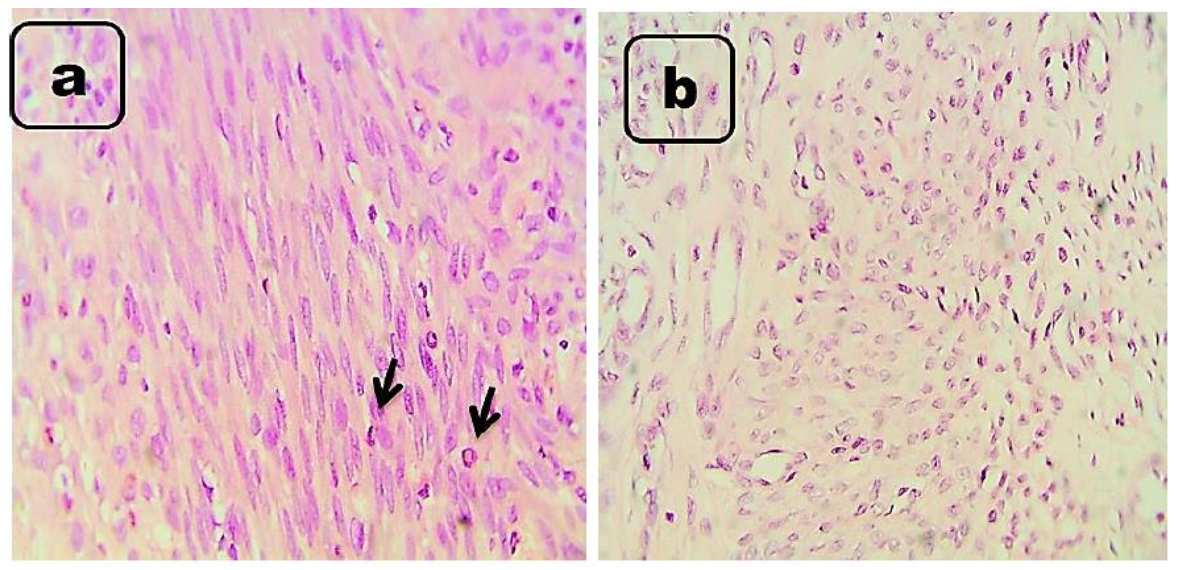

Figure 4. Microscopic picture shows rat uterus at 3 days of gestation shows eosinophils infiltration in myometrium (arrows) (a) in control rats. No eosinophils infiltration is seen in myometrium (b) in dexamethasone treated rats
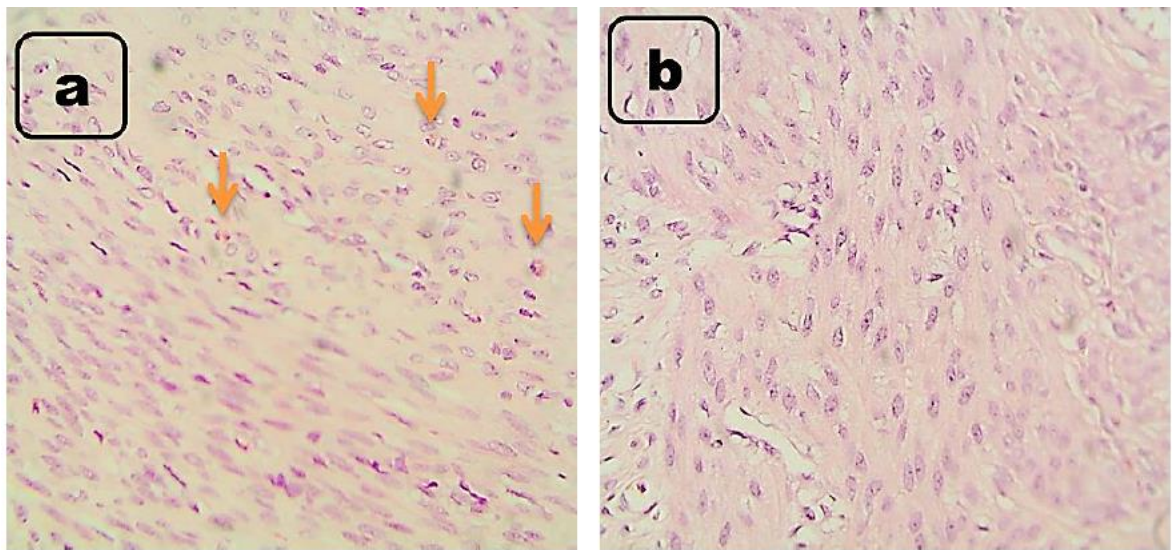

Figure 5. Microscopic picture shows rat uterus at 7 days of gestation shows few eosinophils infiltration in myometrium (arrows) (a) in control rats No eosinophils infiltration is seen in myometrium (b) in dexamethasone treated rats. Statistical analysis of epithelial height and diameter of uterine glands showed that epithelial height increased in dexamethasone treated rats at 5 hours and days 3 and 7of gestation when compared with control group. The increase was significant at 5 hours and days $3 \& 7$ of gestation when compared with control group. Diameter of uterine glands nonsignificantly increased in dexamethasone treated rats in days 3 and 7 of gestation when compared with control groups. 


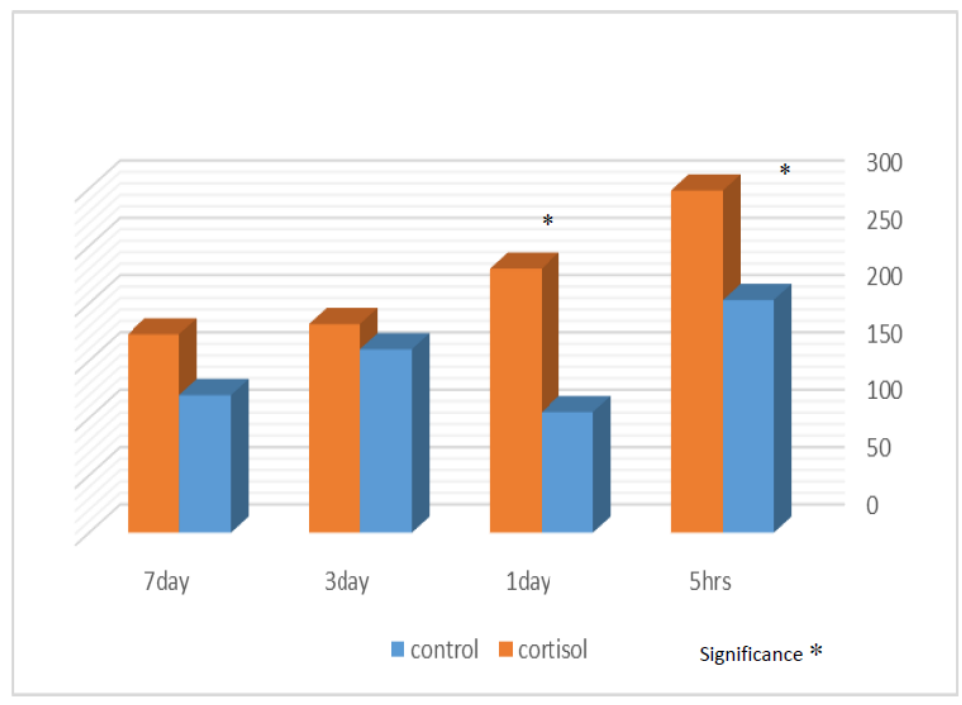

Figure 6. Dexamethasone effect on epithelial height:

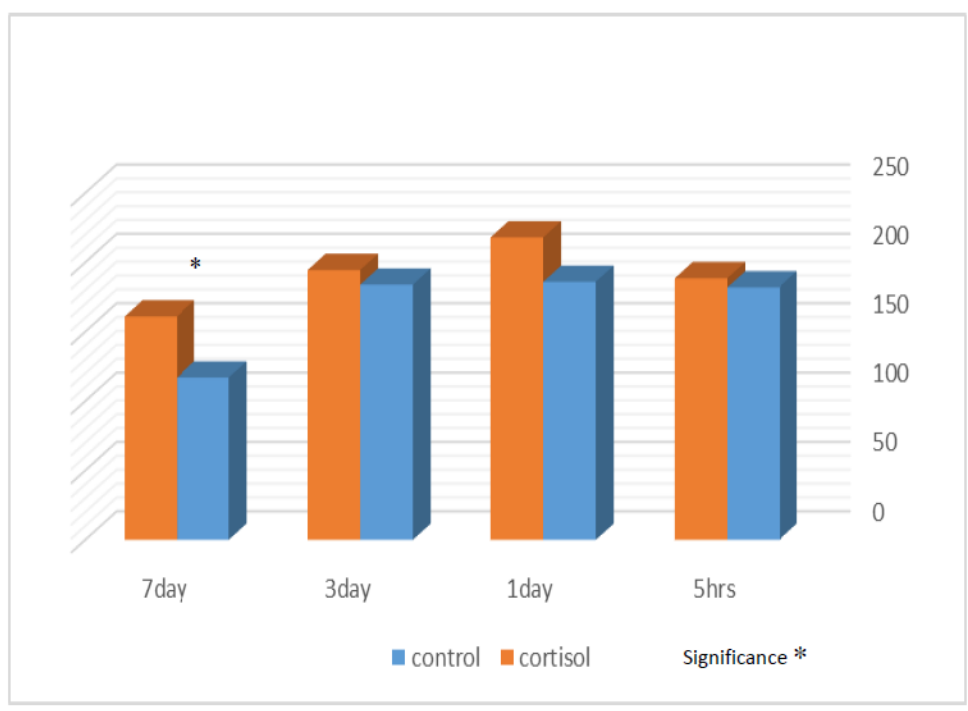

Figure 7. Dexamethasone effect on uterine gland diameter

\section{DISCUSSION}

The result of present investigation was recorded in tables (1-4) and figures (1-7) showed that white blood cells number increased at $5 \mathrm{hrs}$ and 1 day of gestation in dexamethasone group when compared with control group. Neutrophil, basophil and monocyte increased in control group at $5 \mathrm{hrs}$ compared with dexamethasone group. Eosinophil increased at $5 \mathrm{hrs}$ and lymphocyte increased at 3day and 7day in dexamethasone group compared with control group. In contrast with (Yasuhiko et al., 2010) showed that the administration of dexamethasone daily for 10 days led to significant decreases in the numbers of total WBCs, lymphocytes, monocyte, eosinophil and basophil but the number of neutrophils was significantly increased in circulating WBCs in hours following a single injection of dexamethasone with recovery of counts at 24 hours post injection suggests some degree of altered leukocyte localization from the blood to the margins of blood vessels and interstitial space. This may be due to its effect as a potent immunosuppressive agent as inhibiting leukocyte function by interrupting synthesis and actions of cytokines and cause lysis of lymphatic cells. Moreover, (Yasuhiko et al., 2010) showed that the administration of dexamethasone significantly decreased the number of circulating lymphocytes and monocyte 
Glucocorticoids (Gcs) are known to induce neutrophil mobilization from the bone marrow and inhibit apoptosis in circulating neutrophil while promoting migration of neutrophil into the tissues. Thus, glucocorticoids appear to exert different effects on neutrophil and basophil, and may differentially affect their migration or vascular margination.

TNF and CRP increased at 7day in dexamethasone group compared with control group. In contrast with (Coussons et al., 2005) showed that when stress increased, levels of TNF- $\alpha$ and IL-10 decreased.

TAC decreased in dexamethasone group at 5hrs and 7 day of gestation compared with control group. Similarly, (Asayama et al.,1992) showed that glucocorticoids alter the levels of antioxidant enzymes in different tissues and increase the levels of very low-density lipoproteins [VLDL], thus accelerating the oxidation of VLDL by the arterial endothelial cells and so dexamethasone decrease total antioxidant capacity.

Innate immunity refers to relatively non-specific defense mechanisms that are able to respond immediately or within hours to the chemical properties of an antigen (Eder,2009).

Many pro-inflammatory cytokines are released by cells of the innate immune system upon stimulation such as IL-1 $\beta$, IL8, TNF- $\alpha$ and GM-CSF (Lacy and Stow,2011).

The $\mathrm{T}$ helper type 1 immune response activates the macrophages and induces $B$ cells to make corresponding antibodies, and this leads to cell-mediated immunity (Iwasaki and Medzhitov,2010).

Glucocorticoids were known to have a direct inhibitory effect both on innate and adaptive immunity. The effects of GC on the innate immune system include phagocyte function impairment and decreased production of pro-inflammatory mediators (Boumpas et al.,1993).

For adaptive immunity, GC impaired a variety of T-cell functions, cytokine production (such as IL-2, IFN- $\gamma$ ), and induced T-cell apoptosis (Franch imont et al., 1998).

However, study about the effects of prenatal GC on developing immunity is limited. From our data, the TNF$\alpha$ production but not IFN- $\gamma$ was diminished in the dexamethasone group in the long-term. This suggests that innate immunity is more susceptible to prenatal dexamethasone than adaptive immunity. This in agreement with (Vandaele et al. 2010) who showed that Dexamethasone administration by 10 or $20 \mathrm{mg}$ after artificial insemination not improve pregnancy rates; the injection has to be given prior to mating to be able to affect cytokine release. Dexamethasone administration shortly before or at mating is a safe and efficient method to modulate the immune response in selected problem mares.
Progesterone increased in dexamethasone group at 7 day of gestation and estrogen decreased in dexamethasone group compared with control group at which estrogen increased at $5 \mathrm{hrs}$ and 7 days of gestation. Ohrlander et al. (1977) indicated that the progesterone and estrogen concentrations were not significantly affected by dexamethasone treatment during pregnancy in goats but differs from that of (Ahmadabad et al.2016) who reported that progesterone levels decrease in pregnant mice treated with dexamethasone. The differences observed could be attributed to species differences with respect to source of progesterone secretions during pregnancy. Moreover, (Ahmadabad et al., 2016) reported that there is a decrease in progesterone and estrogen levels in pregnant mice treated with dexamethasone and so suggested that dexamethasone does not have negative effects on estrogen and estrogen precursor producing structures like ovaries and adrenal glands (Thurston ,2002).

McDonald et al. (2003) reported that glucocorticoids are involved in the heterologous up regulation of several hormone receptors. The mechanism is probably through regulation of receptor mRNA levels by influencing increase in Progesterone mRNA levels and gene transcription in rats as reported by (Kraus and Katzenellenbogen, 1993).

Interleukin $1 \mathrm{a}$ and interleukin 10 increased at $5 \mathrm{hrs}$ and 1 day in dexamethasone group compared with control group. The increase in interleukin 1a which is proinflammatory cytokine may be in response to semi allogenic foreign embryo at the same time with the increase in interleukin 10 which is anti-inflammatory cytokine to tolerate proinflammatory action of interleukin 1a cytokine for maintenance of pregnancy. In contrast, (Coussons et al.,2007) showed that increased stress was associated with decreased IL-10 in the first and third trimesters of pregnancy.

Dexamethasone has general anti-immune properties and can downregulate both Th1 and Th2 cytokine release (Sun, Yu, Yang, \& Zhang, 2011), suggesting that higher-than-normal levels of dexamethasone might downregulate the inflammatory cytokine balance that is so important for normal pregnancy

Histopathological examination revealed that after five hours of gestation, few eosinophil and congested blood vessels compared with control group which have heavy eosinophil cells in endometrium and in between uterine gland. At one day of gestation, in addition to eosinophilic infiltration polymorphonuclear cells found in myometrium in dexamethasone group. At three days of gestation, eosinophil absent from myometrium of dexamethasone treated group. At 7 days of gestation, eosinophil cells were absent in dexamethasone treated group when compared with control group that contain few eosinophil cells. Height and diameter of uterine gland increased at 5hrs, 3 days and 7 days of 
gestation of dexamethasone treated group compared with control group. However, (Bucca et al., 2008) demonstrated that dexamethasone decreased endometrial odema, fluid accumulation, quality of efflux post-breeding and increased pregnancy rate in mares. Moreover, (Ashwell et al., 2000) showed that anti-inflammatory drugs such as dexamethasone suppress leukocyte migration by binding to intracellular receptors and inhibiting gene expression by binding to negative regulatory promoter regions or through protein interactions.

Similarly, (Sugimoto et al.2003) found that antiinflammatory effects of dexamethasone were mediated by inhibition of leukocyte migration. In contrast, (Deloia et al. 2002) demonstrated that the frequency of uterine macrophages and uNK cells had a direct relationship with serum estrogen levels. It can thus be suggested that the administration of high dose of dexamethasone in pregnant mice during early pregnancy can directly or indirectly alter the frequency of uterine macrophages and uNK cells. Since uterine macrophages and uNK cells play important roles in the secretion of angiogenic and growth factors so decreased frequencies of these cells can change spiral artery remodeling and trophoblast invasion, as well as lead to adverse pregnancy outcomes (Warning et al.,2011).

\section{CONCLUSION}

Use of dexamethasone by $50 \mathrm{mg} / \mathrm{kg}$ in early pregnancy result in disturbance in level of important cytokines for gestation. In addition, decrease leukocyte number in blood and uterine tissue. So, dexamethasone administration not preferable at early period of gestation.

\section{REFERENCES}

Ahmadabad H. N; Jafari S. K; Firizi M N; Abbaspour A. R; Gharib F. G; Ghobadi $Y$, (2016): Pregnancy outcome following administration of high doses of dexamethasone in early pregnancy in Mice. Clin Exp Reprod Med.; 43(1):15-25.

Asayama K; Hayashibe H; Dobashi K;Uchida N; Kato K. (1992): Effect of dexamethasone on antioxidant enzymes in fetal lungs and kidneys. Biol Neonate; 62:136-144

Bakker, J. M; Kavelaars A; Kamphuis P. J; Cobelens P. M; Vugt H. H; Bel F; Heijnen, C. J. (2000): Neonatal dexamethasone treatment increases susceptibility to experimental autoimmune disease in adult rats. J. Immunol. 165, 5932-5937.

Bancroft J. D and Gamble M. (2007): Theory and Practice of Histological Techniques. 5th Ed; Churchill Livingstone, London, UK, pp: 125-138.

Banni M; Messaoudi I.; Said L; El Heni J; Kerkeni A. and Said K. (2010): Metallothionein Gene Expression in Liver of Rats Exposed to Cadmium and Supplemented with Zinc and Selenium. Arch Environ Contam Toxicol, 59:513-519.

Boumpas D.T; Chrousos G.P; Wilder R.L; Cupps T.R; Balow J.E. (1993): Glucocorticoid therapy for immune-mediated diseases: basic and clinical correlates. Ann Intern Med; 119:1198-208.
Bucca S. (2008): The use of dexamethasone administered to mares at breeding time in the modulation of persistent mating induced endometritis. Theriogenology 70 1093-1100.

Coe C. L; Lubach G. R. (2000): Prenatal influences on neuroimmune set points in infancy. Ann. N. Y. Acad. Sci. 917, 468-477.

Cooper M. A; Fehniger T. A; Caligiuri M. A. (2001): The biology of human natural killer-cell subsets. Trends Immunol 22, 633-40.

Coussonsread M.E; Okun M.L; Schmitt M.P; Giese S. (2005): Prenatal stress alters cytokine levels in a manner that may endanger human pregnancy. Psychosom. Med. ;67:625-631.

Coussonsread M.E; Okun M.L; Nettles C. D. (2007): Psychosocial stress increases inflammatory markers and alters cytokine production across pregnancy. Brain Behav. Immun. 21:343-350.

Dealtry G. B; O'Farrell M.K; Fernandez N. (2000): The T helper 2 cells cytokines environment of the placenta. Int Arch Allergy Immunol.; 123(2):107-119.

DeLoia J. A; Stewart-Akers A. M; Brekosky J; Kubik C. J. (2002): Effects of exogenous estrogen on uterine leukocyte recruitment. Fertil Steril; 77:54854.

Dietert R. R. and Lee J. (2003): Susceptibility of the developing immune system to immunosuppressive agents: Differential risk across life stages. Toxicologist72(S-1), 225.

Eder C. (2009): Mechanisms of interleukin-1b release. Immunobiology; 214:543-53.

Ezechi O. C; Makinde O. N; Kalu B. E; Nnatu S. N. (2003):Risk factors for preterm delivery in South Western Nigeria J. Obstet. Gynaecol23:387391.

Faas M. M; Schuiling G. A; Linton E. A; Sargent I. L; Redman C. W.(2000): Activation of peripheral leukocytes in rat pregnancy and experimental preeclampsia. Am J Obstet Gynecol 182(2):351-710.

Fahey A. J; Robins R. A; Kindle K.B; Heery D.M; Constantinescu C. S. (2006): Effects of glucocorticoids on STAT4 activation in human T cells are stimulus-dependent. J Leukoc Biol; 80:133-44.

Felicio L. S; Nelson J.F; Finch C. E. (1984): Longitudinal studies of estrous cyclicity in aging C57BL/6J mice: II. Cessation of cyclicity and the duration of persistent vaginal cornification. Biol Reprod.;31:446-453.

Franchimont D; Louis E; Dewe W; Martens H; Vrindts-Gevaert Y; De Groote D; Belaiche J; Geenen V. (1998): Effects of dexamethasone on the profile of cytokine secretion in human whole blood cell cultures. Regul Pept; 73:59-65.

Goldman S. and Shalev E. (2007): Progesterone receptor profile in the decidua and fetal membrane. Front Biosci 12:634-48.

Gur C; Diav-Citrin O; Shechtman S; Arnon J; Ornoy A. (2004): Pregnancy outcome after first trimester exposure to corticosteroids: a prospective controlled study. Reprod Toxicol; 18:93-101.

Gyorffy Z; Adam S; Kopp M. (2005): Health status of physicians in Hungary: a representative study) Orv. Hetil 146:1383-1391.

Haider S; Knofler M, (2009): Human tumour necrosis factor: physiological and pathological roles in placenta and endometrium. Placenta, 30 111-123.

Hanna N; Hanna I; Hleb M; Wagner E; Dougherty J; Balkundi D; Padbury J; Sharma S. (2000): Gestational age-dependent expression of IL-10 and its receptor in human placental tissues and isolated cytotrophoblasts. Immunol.; 164:5721-5728. 
Hunt J. S; Miller L. and Platt J. S. (1998): Hormonal regulation of uterine macrophages. Dev Immunol 6(1-2):105-10.

Ishiguro T; Takeda J; Fang X; Bronson H. and Olson D. M. (2016): Interleukin (IL)- 1 in rat parturition: IL-1 receptors 1 and 2 and accessory proteins abundance in pregnant rat uterus at term - regulation by progesterone. Physiol Rep, 4 (14), 2016, e12866

Iwasaki A; Medzhitov R. (2010): Regulation of adaptive immunity by the innate immune system. Science; 327:291-5.

Karemaker R; Kavelaars A; Wolbeek M; Tersteeg-Kamperman M; Baerts W; Veen S; Samsom J. F; Visser G. H; Bel F. and Heijnen, C. J. (2008): Neonatal dexamethasone treatment for chronic lung disease of prematurity alters the hypothalamus- pituitary-adrenal axis and immune system activity at school age. Pediatrics 121, e870-e878.

Kinnear P. R. and Gray C. D. (1994): Spss for windows made simple Hove (UK).psychology stress.

Kitzmiller J. L. and Rocklin R. E. (1980): Lack of suppression of lymphocyte MIF production by estradiol, progesterone and human chorionic gonadotropin. J Reprod Immunol 1(5-6):297-306.

Kowalik M. K; Rekawiecki R; Kotwica J. (2013): The putative roles of nuclear and membrane bound progesterone receptors in the female reproductive tract. Reprod Biol 13(4):279-89.

Kraus M. A; Katzenellenbogen N. V. (1993): Regulation of progesterone receptor gene expression in rat uterus: modulation of estrogen action by progesterone and sex steroid hormone antagonists. Endocrinology; 132:2371-824.

Lacy P; Stow J. L. (2011): Cytokine release from innate immune cells: association with diverse membrane trafficking pathways. Blood; 118:918.

Levin E. R. and Pietras R. J. (2008): Estrogen receptors outside the nucleus in breast cancer. Breast Cancer Res. Treat. 108, 351-361

M-Stat, Loh, W. K. W; LaJeunesse, T. C; Hoegh, G. o; Carter, D. A. (2009):Stability of coral-endosymbiont associations during and after a thermal stress event in the southern Great Barrier Reef. Coral reefs Journal .28:3 709-713.

Mcdonald T. J; Franko K. L; Brown J. M; Jenkins S. L; Nathanielsz P. W; Nijland M. J. (2003): Dexamethasone in the last week of pregnancy causes fetal growth retardation but not adult hypertension in rats. J Soc Gynecolo Invest.;32:469-73.

Mesquita A. R; Wegerich Y; Patchev A. V; Oliveira M; Leao P; Sousa N. and Almeida O. F. (2009): Glucocorticoids and neuro- and behavioural development. Semin. Fetal Neonatal Med. 14, 130-135.

Ohrlander S; Gennser G; Batra S. (1977): Effects of detamethasone administration on estrone, estradiol-17 $\beta$, and progesterone in maternal plasma and amniotic fluid. Obstet Gynecol.; 49:148-53.

Parr M. B; Tung H. N; and Parr E. L. (1986): The ultrastructure of the rat primary decidual zone, Am. J. Anat. 176: 423-436.

Rae M.T; Niven D; Ross A; Forster T; Lathe R; Critchley H. O; Ghazal P. and Hillier S.G. (2004): Steroid signalling in human ovarian surface epithelial cells: the response to interleukin-1a determined by microarray analysis. Journal of Endocrinology 183 19-28.

Rasmussen S; Larsena A. S; Thomsena S.T; Kehlert H. (1998): Intra-articular glucocorticoid, bupivacaine and morphine reduces pain, inflammatory response and convalescence after arthroscopic meniscectomy. Pain, 78:131-134
Sallinen K; Verajankorva E; Pollanen P. (2000): Expression of antigens involved in the presentation of lipid antigens and induction of clonalanergy in the female reproductive tract. J Reprod Immunol; 46:91-101.

Shynlova O; Dorogin A; Li Y. and Lye S. (2014): Inhibition of infection-mediated preterm birth by administration of broad spectrum chemokine inhibitor in mice. J. Cell. Mol. Med. Vol 18, No 9, pp. 1816-1829.

Sugimoto Y; Ogawa M; Tai N; Kamei C. (2003): Inhibitory effects of glucocorticoids on rat eosinophil superoxide generation and chemotaxis chemotaxis. Int Immunopharmacol; 3:845-52.

Sun L; Yu G; Yang S; Zhang L. (2011): Effects of hydrocortisone on the differentiation of human $T$ helper 2 cells. Scandanavian Journal of Immunology.;73(3):208-214.

Thompson J. G; Lane M. and Robertson S. A. (2005): Adaptive responses of embryos to their microenvironment and consequences for postimplantation development. In Early life origins of health and disease, Landes Bioscience, pp.58-69.

Thurston L. M. (2002): Ovarian modulators of 11beta-hydroxysteroid dehydrogenase (11betaHSD) activity in follicular fluid from gonadotrophin-stimulated assisted conception cycles. J Reprod.;124(6):801-12.

Uchenna I. N; Fidelis E. E. (2005): Serum ascorbic acid levels during pregnancy in Enugu, Nigeria. J Coll Med ;10(1):43-5

Vandaele H; Daels P; Piepers S; Le-Blanc M. (2010): Effect of postinsemination dexamethasone treatment on pregnancy rates in mares. Anim. Reprod. Sci. 121S, S110-S112.

Veenstravan-Nieuwenhoven A. L; Bouman A; Moes H; Van der Schaaf, G.C.J., Schuiling, G.A., Heineman, M.J., de Leij, F.M.L.H., Santema, J., Faas, M.M., (2002): Cytokine production by NK-cells as well as by lymphocytes in pregnant women as compared with women in the follicular phase of the ovarian cycle. Fertil. Steril. 77.

Warning J. C; Mccracken S. A; Morris J. M. A. (2011): balancing act: mechanisms by which the fetus avoids rejection by the maternal immune system. Reproduction; 141:715-24.

Yasuhiko O; Natsuko A; Hitoshi O; Shogo S; Yuko S; Hiroko S; Shoko A; Shunta A; Takamasa B; Jun T; Kaoru T. and Kazuhiko I. (2010): Acute and subacute effects of dexamethasone on white blood cells in rats Journal of Health Science, 56(2) 215-220.

Yuan J. S; Reed A; Chen F. and Stewart C.N. (2006): Statistical analysis of realtime PCR data. BMC Bioinformatics 2006, 7:85.

Zone M; Wanke M; Rebuelto M; Loza M; Mestre J; Duchene A. (1995): Termination of pregnancy in dogs by oral administration of dexamethasone. Theriogenology; 43:487-94. 